\title{
PURCHASE INTENTION PRODUK FROZEN FOOD BERDASARKAN PERCEIVED QUALITY DAN PRICE FAIRNESS
}

\author{
Wildan Radista Wicaksana \\ Universitas Airlangga Surabaya \\ wildanradista@yahoo.com \\ Bella Paramastri \\ Universitas Airlangga Surabaya \\ paramastribella@gmail.com \\ Helmina Ardyanfitri \\ UIN Sunan Ampel Surabaya \\ helmina.ardyanfitri@uinsby.ac.id
}

\begin{abstract}
Abstrak
Penelitian ini bertujuan untuk menguji pengaruh persepsi kualitas (Perceived Quality) dan kewajaran harga (Price Fairness) terhadap minat beli (Purchase Intention) pada produk frozen food. Populasi dari penelitian ini adalah konsumen yang berada di Surabaya. Sampel dari penelitian adalah 60 orang konsumen yang pernah melakukan pembelian frozen food. Metode penelitian yang digunakan adalah kuantitatif dengan teknik Analisa statistika yang digunakan dalam penelitian adalah SEM-PLS (Structural Equation Modeling-Partial Least Square). Hasil penelitian menunjukkan bahwa terdapat hubungan/pengaruh positif antara perceived quality dengan price fairness dan perceived quality dengan purchase intention, sedangkan tidak ada hubungan/pengaruh antara price fairness dan purchase intention. Pengaruh yang paling kuat adalah perceived quality terhadap price fairness. Sehingga konsumen menilai perceived quality merupakan hal yang penting bagi produk frozen food dan minat beli konsumen terhadap produk frozen food tidak ditentukan oleh price fairness. Keywords: Covid 19; Frozen Food; Perceived Quality; Price Fairness; Purchase Intention
\end{abstract}

\section{PENDAHULUAN}

Pangan merupakan salah satu kebutuhan dasar dalam kehidupan manusia hingga kapan pun. Teknologi pengolahan pangan semakin berkembang dari waktu ke waktu. Untuk memenuhi kebutuhan pangan, saat ini masyarakat lebih menyukai makanan yang praktis, ekonomis, dan mudah dalam penyajiannya. Produk pangan siap saji (ready to serve food) merupakan salah satu jenis pangan yang dapat memenuhi kriteria tersebut. Menurut MMI (2009), makanan siap saji adalah segala sesuatu makanan yang telah dimasak dan disimpan dengan menggunakan bahan pengawet ataupun dengan berbagai metode penyimpanan. Salah satu produk makanan siap saji tersebut adalah produk makanan olahan beku (frozen food). Frozen food merupakan produk makanan yang telah dikemas dan disimpan beku 
dalam freezer, sehingga siap untuk dimasak dan dikonsumsi pada waktu tertentu (Anggraini, 2010).

Frozen food pada umumnya dipilih oleh masyarakat karena mudah disajikan, higienis, harga terjangkau, serta praktis. Dalam hal ini, perubahan gaya hidup masyarakat dapat mempengaruhi pola konsumsi masyarakat akan produk pangan. Hal ini menjadi salah satu alasan dan peluang bagi industri pangan untuk masuk dalam bisnis frozen food. Saat ini, industri frozen food semakin berkembang di berbagai tingkatan, mulai dari industri rumah tangga hingga industri raksasa FMCG (Fast Moving Customer Goods), seperti Wonokoyo Group dengan merek Goldstar, Belfoods Indonesia dengan merek Belfoods, PrimaFood International dengan merek Fiesta, dan lainnya.

Dengan banyaknya jumlah pelaku usaha pada industri frozen food, hal tersebut mendorong terjadinya persaingan antar perusahaan untuk memenangkan hati konsumen. Persaingan ini ditentukan oleh adanya niat membeli (purchase intention) konsumen sebelum akhirnya membeli sebuah produk. Morinez et al. (2007) menjelaskan bahwa niat membeli (purchase intention) merupakan sebuah situasi bagi konsumen untuk cenderung melakukan pembelian produk atau layanan tertentu dalam kondisi tertentu. Dalam upaya untuk meningkatkan niat membeli konsumen, dipengaruhi oleh dua faktor utama, yaitu kualitas makanan yang dirasakan (perceived quality) dan jumlah uang atau harga yang harus dibayarkan (price fairness).

Selain itu, persaingan juga dipengaruhi oleh faktor eksternal, yang berasal dari lingkungan. Salah satu faktor eksternal adalah adanya wabah penyakit. Cohn (2003) menjelaskan bahwa fenomena wabah penyakit yang melanda Eropa antara tahun 1347 dan 1351 mengubah wajah sosial dan ekonomi sistem abad pertengahan dan terbukti menjadi peristiwa besar dalam sejarah Eropa. Januari tahun 2020, dunia mengalami bencana dengan adanya pandemi Covid-19 yang mempengaruhi banyak sektor ekonomi. Dengan adanya pandemi Covid-19 tersebut, berpengaruh pada sektor pangan, terutama industri frozen food yang terus berusaha untuk bertahan dalam menghadapi pandemi tersebut dengan memberikan kualitas yang baik dan menawarkan harga yang dapat diterima oleh masyarakat. Hal tersebut mempengaruhi niat membeli konsumen terhadap produk pangan, dimana pada penelitian ini berfokus pada produk frozen food.

Penelitian ini meneliti tentang meningkatkan niat membeli konsumen dengan memperhatikan faktor perceived quality dan price fairness selama pandemi Covid-19 khususnya di Indonesia. Dengan demikian, penelitian ini bertujuan untuk 
menguji pengaruh persepsi kualitas (Perceived Quality) dan kewajaran harga (Price Fairness) terhadap minat beli (Purchase Intention) pada produk frozen food.

\section{KAJIAN PUSTAKA DAN PENGEMBANGAN HIPOTESIS Persepsi Kualitas (Perceived Quality)}

Perceived quality merupakan persepsi konsumen terhadap kualitas atau keunggulan suatu produk atau layanan dibandingkan dengan produk atau layanan lainnya (Keller, 2008). Persepsi kualitas konsumen tidak berwujud sehingga produsen harus dapat memahami persepsi konsumen.

Produk atau layanan yang berkualitas dapat menjadi sebuah keunggulan bersaing bagi produk atau layanan tersebut. Hal ini sesuai dengan pendapat Zeeshan (2013) bahwa kualitas dapat digunakan sebagai sebuah keunggulan kompetitif.

Persepsi kualitas adalah persepsi pelanggan tentang kualitas umum atau keunggulan satu produk atau layanan, dengan perhatian pada tujuan produk atau layanan tersebut, dibandingkan dengan alternatif lain (Keller, 2008).

Kualitas yang dipersepsikan dapat didefinisikan sebagai persepsi konsumen tentang kualitas umum atau keunggulan dari satu produk atau layanan dengan mempertimbangkan kasus tujuan yang diharapkan dibandingkan dengan alternatif lain. Persepsi kualitas adalah perasaan umum dan tidak berwujud tentang merek. Namun, persepsi kualitas biasanya didasarkan pada dimensi utama yang terdiri dari spesifikasi produk (keandalan, kinerja, dan merek). Kualitas berguna untuk menciptakan keunggulan kompetitif (Zeeshan, 2013).

H1: Terdapat pengaruh positif Perceived Quality terhadap Price Fairness

\section{Kewajaran Harga (Price Fairness)}

Harga merupakan sejumlah uang yang harus dikorbankan oleh konsumen untuk mendapatkan suatu barang atau jasa (Bei et al., 2006). Konsumen akan mempertimbangkan hubungan antara harga dan harapan konsumen mengenai manfaat yang didapatkan dari suatu barang atau jasa yang akan konsumen beli. Oleh karena itu, harga jual akan dibandingkan oleh konsumen terhadap pengalaman sebelum konsumen melakukan pembelian atau suatu harapan yang adil (Hermann $e t$ al., 2007).

Konsumen merasa bahwa manfaat yang ditawarkan oleh suatu produk atau jasa sehubungan dengan pengorbanan tinggi konsumen, maka konsumen akan merasa bahwa harga adalah adil, hal ini disebut sebagai price fairness (Monroe, 1985). Price fairness merupakan sebuah persepsi konsumen dimana perbedaan 
antara harga yang diterima layak untuk dibandingkan dengan yang lain, dapat dipertimbangkan atau harga tersebut dapat diterima (Matzler, 2007).

Herman (2001) menunjukkan bahwa harga yang dirasakan oleh konsumen merupakan faktor penting yang digunakan konsumen dalam menilai kualitas. Kewajaran harga (price fairness) sudah digambarkan sebagai suatu hasil atau proses untuk menilai hasil yang layak diterima atau adil (Martin et al., 2007). Jika harga yang dirasakan konsumen lebih rendah, maka sebanding dengan pengorbanan yang diberikan konsumen juga akan rendah.

Sebaliknya, harga yang dirasakan konsumen lebih tinggi, maka sebanding dengan pengorbanan yang diberikan konsumen juga akan tinggi. Menurut Martin (2007), ada tiga acuan konsumen untuk menilai price fairness, yaitu harga di masa lalu, harga yang digunakan oleh pesaing, harga yang dicantumkan saat ini. H2: Terdapat pengaruh positif Price Fairness terhadap Purchase Intention

\section{Niat Pembelian (Purchase Intention)}

Keputusan konsumen dalam melakukan suatu pembelian merupakan hal yang kompleks. Ghosh (1990) menyatakan bahwa niat pembelian merupakan tools yang efektif dalam memprediksi proses pembelian yang dilakukan oleh konsumen. Niat pembelian atau purchase intention adalah jenis pengambilan keputusan yang mempelajari konsumen dalam melakukan pembelian merek tertentu (Shah et al., 2012).

Purchase intention merupakan preferensi seorang konsumen dalam melakukan pembelian produk atau jasa (Keller, 2001). Niat pembelian yang muncul pada konsumen dapat berubah oleh adanya pengaruh harga, persepsi kualitas produk atau layanan dan persepsi nilai (Zeithaml, 1988). Morinez et al. (2007) juga menyatakan bahwa niat pembelian merupakan sebuah situasi bagi konsumen untuk cenderung melakukan pembelian produk atau layanan tertentu dalam kondisi tertentu.

H3: Terdapat pengaruh positif Perceived Quality terhadap Purchase Intention

\section{METODE PENELITIAN}

Desain penelitian ini adalah pendekatan kuantitatif dengan melakukan pengujian suatu hipotesis. Penelitian ini menggunakan data-data primer yang terukur serta menggunakan metode analisis statistik untuk mendapatkan kesimpulan yang dapat digeneralisasi. 
Pengambilan sampel dari penelitian ini menggunakan nonprobability sampling (Zikmund et al., 2013). Jumlah sampel yang digunakan dalam penelitian ini adalah 60 sampel. Pengumpulan data dilakukan dengan menyebarkan kuisioner kepada individu yang sudah pernah membeli dan mengonsumsi frozen food selama pandemi Covid-19 khususnya di Kota Surabaya. Penyebaran kuisioner dilakukan secara online dengan membagikan link (tautan) kuisioner kepada calon responden.

Teknik analisis data yang digunakan dalam penelitian ini adalah SEM-PLS (Structural Equation Modeling-Partial Least Square). Teknik analisis SEM-PLS bertujuan untuk memprediksi pengaruh dari variabel independen (bebas) terhadap variabel dependen (terikat), serta menjelaskan hubungan teoritis antara kedua variabel, dengan menggunakan inner dan outer model.

\section{HASIL DAN PEMBAHASAN}

\section{Karakteristik Jawaban Responden}

Mayoritas dari responden adalah berjenis kelamin laki-laki, dengan presentase sebesar $51 \%$. Berdasarkan usia, mayoritas responden berusia antara 2030 tahun, dengan presentase sebesar $80 \%$. Berdasarkan latar belakang pendidikan terakhir, mayoritas responden memiliki pendidikan terakhir setingkat Strata 1 (S-1), dengan presentase sebesar 78\%. Berdasarkan jenis pekerjaan, mayoritas responden memiliki pekerjaan/bekerja sebagai karyawan swasta, dengan presentase sebesar $40 \%$. Berdasarkan penghasilan per bulan, mayoritas responden berpenghasilan sebesar 3-5 juta rupiah per bulan, dengan presentase sebesar $48 \%$.

\section{Tabel 1. KARAKTERISTIK RESPONDEN PENELITIAN}

\begin{tabular}{|l|c|c|c|}
\hline \multirow{1}{*}{ Item } & Deskripsi & Jumlah & Presentase \\
\hline \multirow{3}{*}{ Jenis Kelamin } & Laki-laki & 32 & $53 \%$ \\
\cline { 2 - 4 } & Perempuan & 28 & $47 \%$ \\
\cline { 2 - 4 } & Total & $\mathbf{6 0}$ & $\mathbf{1 0 0 \%}$ \\
\hline \multirow{4}{*}{ Usia } & $<20$ tahun & 3 & $5 \%$ \\
\cline { 2 - 4 } & $20-30$ tahun & 49 & $82 \%$ \\
\cline { 2 - 4 } & $31-40$ tahun & 6 & $10 \%$ \\
\cline { 2 - 4 } & $41-50$ tahun & 2 & $3 \%$ \\
\cline { 2 - 4 } & Total & $\mathbf{6 0}$ & $\mathbf{1 0 0 \%}$ \\
\hline \multirow{3}{*}{$\begin{array}{l}\text { Pendidikan } \\
\text { Terakhir }\end{array}$} & SMA/SMK & 7 & $12 \%$ \\
\cline { 2 - 4 } & Strata $1(\mathrm{~S}-1)$ & 47 & $78 \%$ \\
\cline { 2 - 4 } & Strata 2 (S-2) & 6 & $10 \%$ \\
\cline { 2 - 4 } & Strata 3 (S-3) & 0 & $0 \%$ \\
\cline { 2 - 4 } & Total & $\mathbf{6 0}$ & $\mathbf{1 0 0 \%}$ \\
\hline
\end{tabular}




\begin{tabular}{|c|c|c|c|}
\hline Item & Deskripsi & Jumlah & Presentase \\
\hline \multirow{5}{*}{ Pekerjaan } & Wiraswasta & 7 & $12 \%$ \\
\cline { 2 - 4 } & Karyawan Swasta & 24 & $40 \%$ \\
\cline { 2 - 4 } & Karyawan & 4 & $7 \%$ \\
\cline { 2 - 4 } & Pegawai Negeri Sipil (PNS) & 10 & $17 \%$ \\
\cline { 2 - 4 } & Lain-lain & 15 & $25 \%$ \\
\cline { 2 - 4 } & Total & $\mathbf{6 0}$ & $\mathbf{1 0 0 \%}$ \\
\hline \multirow{5}{*}{ Penghasilan } & Rp. 3 juta $-(<)$ Rp. 5 juta & 29 & $48 \%$ \\
\cline { 2 - 4 } & Rp. 7 juta $-(<)$ Rp. 9 juta & 12 & $20 \%$ \\
\cline { 2 - 4 } & Rp. 5 juta $-(<)$ Rp. 7 juta & 5 & $8 \%$ \\
\cline { 2 - 4 } & Rp. 9 juta $-(<)$ Rp. 11 juta & 8 & $13 \%$ \\
\cline { 2 - 4 } & Rp. (>) 11 juta & 6 & $10 \%$ \\
\cline { 2 - 4 } & Total & $\mathbf{6 0}$ & $\mathbf{1 0 0 \%}$ \\
\hline
\end{tabular}

Sumber: Hasil Pengolahan Data Peneliti (2020)

Berikut merupakan deskripsi jawaban responden untuk setiap variabel; perceived quality, price fairness, dan purchase intention. Jawaban dideskripsikan berdasarkan frekuensi atau jumlah kesesuaian pendapat responden dengan pernyataan yang ada pada kuisioner. Masing-masing skor akan bernilai 1-5 dengan perhitungan rata-rata dari setiap variabel yang sudah dikategorikan. Nilai tertinggi adalah 5 dan nilai terendah adalah 1, dengan jumlah kelas 5 . Interval kelas untuk lima variabel dengan jumlah kelas 5 adalah 0,80 . 
Wildan Radista Wicaksana, Bella Paramastri, Helmina Ardyanfitri

Purchase Intention Produk Frozen Food Berdasarkan Perceived Quality dan

Tabel 2. DESKRIPSI JAWABAN RESPONDEN

\begin{tabular}{|c|l|c|c|}
\hline \multicolumn{1}{|c|}{ Pernyataan } & Mean & Kategori \\
\hline PQT-1 & Brand image dari produk frozen food adalah baik. & 3.877 & Tinggi \\
\hline PQT-2 & Rasa dari produk frozen food adalah baik. & 3.985 & Tinggi \\
\hline PQT-3 & Kemasan dari produk frozen food adalah baik. & 4.215 & $\begin{array}{c}\text { Sangat } \\
\text { Tinggi }\end{array}$ \\
\hline PQT-4 & $\begin{array}{l}\text { Saya percaya terhadap informasi yang tertera pada kemasan } \\
\text { produk frozen food. }\end{array}$ & 4.000 & Tinggi \\
\hline PQT-5 & $\begin{array}{l}\text { Saya yakin dengan kandungan dan bahan-bahan yang digunakan } \\
\text { pada produk frozen food. }\end{array}$ & 3.381 & Tinggi \\
\hline PQT-6 & $\begin{array}{l}\text { Produk frozen food aman karena telah diolah dan dimasak secara } \\
\text { efektif. }\end{array}$ & 3.877 & Tinggi \\
\hline PRF-1 & $\begin{array}{l}\text { Harga produk frozen food yang ditawarkan di pasaran masuk } \\
\text { akal. }\end{array}$ & 4.000 & Tinggi \\
\hline PRF-2 & Harga produk frozen food yang ditawarkan di pasaran wajar. & 4.000 & Tinggi \\
\hline PRF-3 & $\begin{array}{l}\text { Harga produk frozen food yang ditawarkan di pasaran dapat saya } \\
\text { terima }\end{array}$ & 4.062 & Tinggi \\
\hline PIN-1 & Saya akan terus membeli produk frozen food. & 3.538 & Tinggi \\
\hline PIN-2 & Saya akan membeli produk frozen food setiap minggunya. & 3.385 & $\begin{array}{l}\text { Cukup } \\
\text { Tinggi }\end{array}$ \\
\hline PIN-3 & Saya akan lebih sering membeli produk frozen food. & 3.231 & $\begin{array}{l}\text { Cukup } \\
\text { Tinggi }\end{array}$ \\
\hline
\end{tabular}

\section{Sumber: Hasil Pengolahan Data Peneliti (2020)}

\section{Analisis Model dan Pengujian Hipotesis}

- Evaluasi Outer Model

Nilai composite reliability untuk variabel perceived quality, price fairness, dan purchase intention adalah $>0.6$, hal tersebut menunjukkan bahwa variabelvariabel yang ada dalam model penelitian ini memiliki reliabilitas yang baik. Nilai AVE untuk variabel perceived quality, price fairness, dan purchase intention adalah $>0.5$. 
Tabel 3. EVALUASI COMPOSITE RELIABILITY DAN CONVERGENT VALIDITY

\begin{tabular}{|c|c|c|c|c|c|}
\hline Variabel/ & Cronbach's & \multicolumn{2}{|c|}{ Composite Reliability } & \multicolumn{2}{|c|}{ Average Variance Extracted } \\
\cline { 3 - 3 } Konstruk & Alpha & Hasil & Syarat & Hasil & Syarat \\
\hline PQT & 0.810 & 0.864 & & 0.520 & \multirow{2}{*}{$>0.5$} \\
\cline { 1 - 2 } & PRF & 0.874 & 0.923 & 0.799 & \\
\hline PIN & 0.861 & 0.914 & & 0.780 & \\
& &
\end{tabular}

Sumber: Hasil Pengolahan Data Peneliti (2020)

Skor cross loading masing-masing indikator terhadap variabel laten masing-masing lebih besar dibandingkan dengan skor cross loading indikator tersebut terhadap variabel laten lainnya yang ada dalam model penelitian. Hal tersebut menunjukkan bahwa setiap indikator dalam penelitian ini memiliki convergent validity dan discriminant validity yang baik.

Tabel 4. EVALUASI DISCRIMINANT VALIDITY

\begin{tabular}{|c|c|c|c|}
\hline & PIN & PQT & PRF \\
\hline PIN-1 & 0.860 & 0.320 & 0.191 \\
\hline PIN-2 & 0.878 & 0.269 & 0.080 \\
\hline PIN-3 & 0.910 & 0.392 & 0.331 \\
\hline PQT-1 & 0.252 & 0.715 & 0.441 \\
\hline PQT-2 & 0.510 & 0.692 & 0.278 \\
\hline PQT-3 & 0.057 & 0.522 & 0.362 \\
\hline PQT-4 & 0.185 & 0.757 & 0.346 \\
\hline PQT-5 & 0.347 & 0.867 & 0.403 \\
\hline PQT-6 & 0.189 & 0.731 & 0.451 \\
\hline PRF-1 & 0.122 & 0.503 & 0.878 \\
\hline PRF-2 & 0.256 & 0.482 & 0.933 \\
\hline PRF-3 & 0.287 & 0.426 & 0.869 \\
\hline
\end{tabular}

Sumber: Hasil Pengolahan Data Peneliti (2020) 


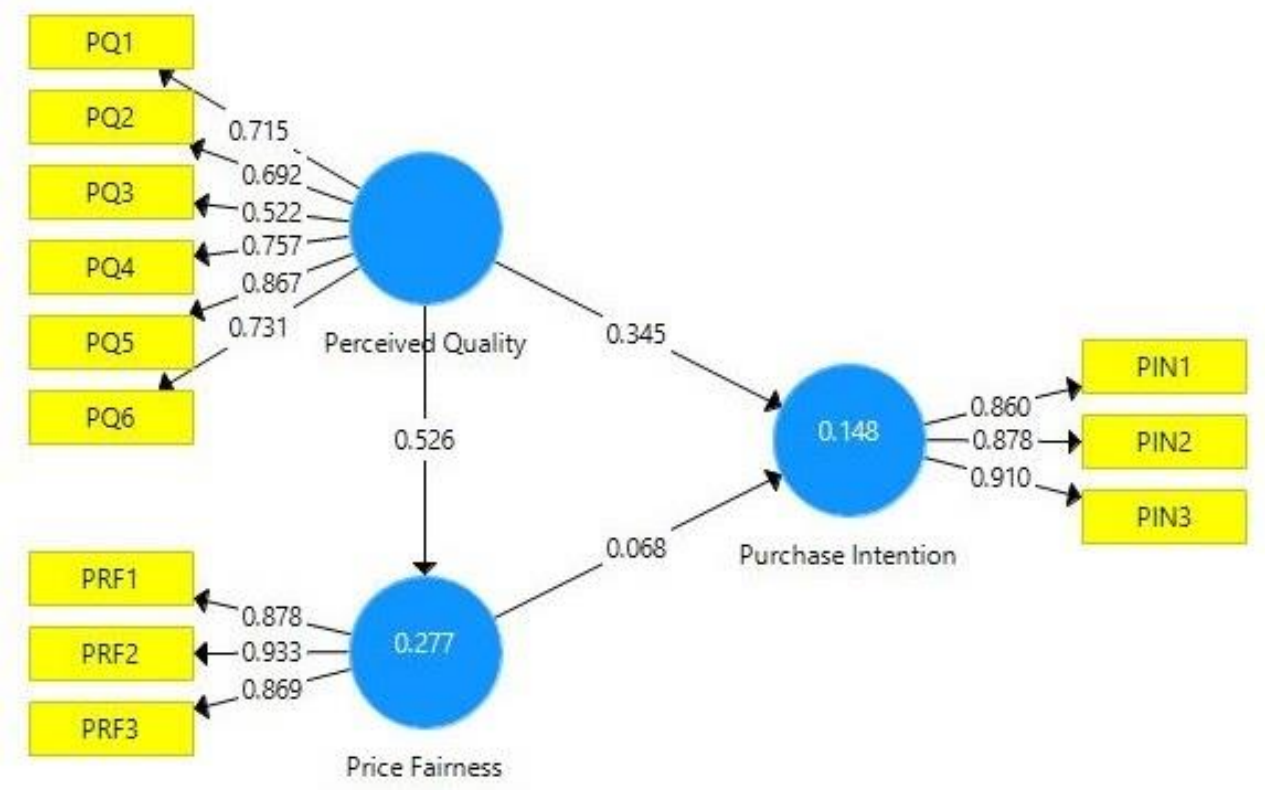

Sumber: Hasil Pengolahan Data Peneliti (2020)

\section{Gambar 1. HASIL EVALUASI OUTER MODEL}

\section{- Evaluasi Inner Model}

Terdapat tiga jalur yang diuji dalam model penelitian ini. Data path coefficient menunjukkan bahwa terdapat hubungan/pengaruh positif antara perceived quality dengan price fairness dan perceived quality dengan purchase intention; sedangkan tidak ada hubungan/pengaruh antara price fairness dan purchase intention. Pengaruh yang paling kuat adalah perceived quality terhadap price fairness.

Tabel 5. EVALUASI PATH COEFFICIENT DAN UJI SIGNIFIKANSI

\begin{tabular}{|c|c|c|c|c|c|}
\hline Hipotesis & Variabel & Path Coefficient & T Statistics & P Value & Keterangan \\
\hline H1 & PQT -> PRF & 0.541 & 5.989 & 0.000 & Berpengaruh dan signifikan \\
\hline H2 & PRF -> PIN & 0.056 & 0.479 & 0.632 & Tidak berpengaruh \\
\hline H3 & PQT -> PIN & 0.374 & 2.766 & 0.006 & Berpengaruh dan signifikan \\
\hline
\end{tabular}

Sumber: Hasil Pengolahan Data Peneliti (2020) 


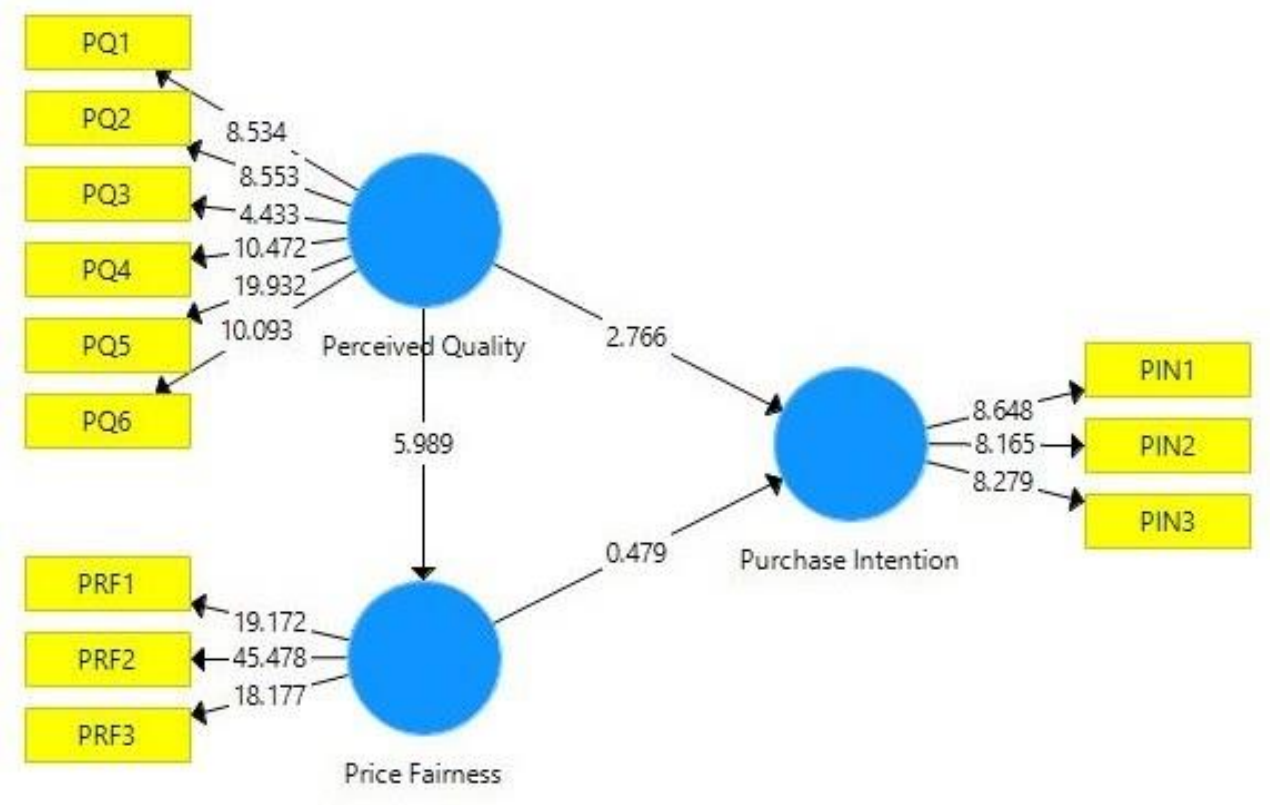

Sumber: Hasil Pengolahan Data Peneliti (2020)

Gambar 2. HASIL EVALUASI INNER MODEL

\section{KESIMPULAN}

Kesimpulan penelitian ini adalah adanya hubungan/pengaruh positif antara perceived quality dengan price fairness. Kemudian adanya hubungan/pengaruh positif antara perceived quality dengan purchase intention. Sedangkan tidak ada hubungan/pengaruh antara price fairness dan purchase intention. Dari ketiga variabel, pengaruh yang paling kuat adalah hubungan/pengaruh positif antara perceived quality terhadap price fairness. Sehingga minat beli (Purchase Intention) konsumen terhadap produk frozen food tidak dipengaruhi oleh kewajaran harga (Price Fairness). Namun minat beli (Purchase Intention) konsumen terhadap produk frozen food dapat dipengaruhi oleh persepsi kualitas (Perceived Quality) yang diterima oleh konsumen. Selain itu, apabila persepsi kualitas (Perceived Quality) yang diperoleh konsumen tinggi, maka konsumen juga bersedia untuk membeli produk frozen food dengan harga tinggi.

Keterbatasan dalam penelitian ini dapat diketahui bahwa produk frozen food terdiri atas berbagai macam jenis, seperti bakso, olahan daging, nugget, sosis, 
siomay, sayur, dan lain-lain. Sedangkan dalam penelitian ini tidak menjelaskan jenis produk frozen food tertentu yang diteliti. Dampaknya adalah ketika responden melakukan pengisian kuesioner akan muncul pertanyaan mengenai jenis frozen food yang digunakan dalam pertanyaan kuesioner. Kemudian penelitian dilaksanakan pada kondisi pandemi Covid19 sehingga tidak merepresentasikan kondisi normal.

Untuk penelitian selanjutnya, dapat dilakukan dengan menambah variabel penelitian serta dapat spesifik terhadap jenis produk frozen food tertentu. Kemudian penelitian selanjutnya dapat menggunakan lebih banyak sampel penelitian dan lingkup penelitian di kota lainnya atau bahkan se-Indonesia.

\section{DAFTAR PUSTAKA}

Cohn, S. K. (2003). The Black Death Transformed: Disease and Culture in Early Renaissance Europe. New York: Oxford University Press.

Darmawan, I. (2006). Pembangunan Manusia Sebagai Sarana Pemberdayaan Masyarakat Miskin. Jurnal Economia, 2(1): 1-11.

Ebel, R.L. \& Frisbie, D.A. (1991). Essential Of Educational Measurement (5 $^{\text {th }}$ Edition). New Delhi: Prentice-Hall, Inc.

Islam, S. M., Kalam, A., \& Fahmida, A. (2018). Factors Affecting Customers' Brand Choice Behavior of Semi Processed Frozen Food Products: A Study in Khulna City, Bangladesh. Universal Journal of Management, 6(8): 273-279.

Keller,K. L. (2008). Strategic Brand Management. Building, Measuring, and Managing Brand Equity. 3 Ed. ,New Jersey: Pearson Education International.

Konuk, F. A. (2019). The influence of perceived food quality, price fairness, perceived value and satisfaction on customers' revisit and word-of-mouth intentions towards organic food restaurants. Journal of Retailing and Consumer Services, 50, 103-110.

Krugman, P.R., (2012). International Economics: Theory \& Policy $\left(9^{\text {th }}\right.$ Edition). Boston: Addison-Wesley.

Kuncoro, M. (2009). Metode Riset untuk Bisnis \& Ekonomi: Bagaimana Meneliti \& Menulis Tesis? (Edisi 3). Jakarta: Erlangga.

Mirabi, V., Akbariyeh, H. \& Tahmasebifard, H., (2015). A study of factors affecting on customers purchase intention. Journal of Multidisciplinary Engineering Science and Technology (JMEST), 2(1). 
Phan, T. \& Mai, P. (2016). Determinants Impacting Consumers? Purchase Intention: The Case of Fast Food in Vietnam. International Journal of Marketing Studies.

Sadilek, T. (2019). Perception of Food Quality by Consumers : Literature Review. European Research Studies Journal, 22(1).

Saifullah, A., Ahmad, N., Ahmed, R., \& Khalid, B. (2014). Frozen Food Revolution: Investigating How Availability of Frozen Food Affects Consumer Buying Behavior. International Journal of Economics, Commerce and Management, 2(8): 2348-2386.

Shah, H., Aziz, A., Jaffari, A. R., Waris, S., Ejaz, W., Fatima, M. \& Sherazi., K. (2012), The Impact of Brands on Consumer Purchase Intentions. Asian Journal of Business Management 4(2): 105-110.

Tashiro, S., \& Lo, C. P. (2012). Gender Difference in the Allocation of Time: Preparing Food Cooked at Home Versus Purchasing Prepared Food. Food, Culture \& Society, 15(3): 455-471.

Yelle, L.E. (1980). Industrial Life Cycles and Learning Curves: Marketing and Production Interaction. Industrial Marketing Management, 9(4): 311-318. 